\title{
CIDADANIA E DIREITO À JUSTIÇA: UMA ABORDAGEM TEÓRICA SOBRE O PAPEL DA MAGISTRATURA BRASILEIRA NA CONFIGURAÇÃO DE UM CIDADÃO PLENO
}

\author{
Hugo Bridges Albergarial
}

\begin{abstract}
RESUMO: O processo de aquisição de direitos civis, políticos e sociais, e a possibilidade de configuração de um cidadão pleno é debate atual no campo acadêmico. Junto a isso, o desejo de se fortificar as instituições políticas para que se possa vislumbrar uma sociedade mais igualitária é tema tanto na academia, quanto no plano de aplicação de políticas públicas e desenvolvimento social. Dentro do campo dos direitos civis, o direito à justiça tem se mostrado importante fator de inacessibilidade dos indivíduos brasileiros à condição de cidadãos plenos, a partir do conceito abordado por T. H. Marshall. Não ignorando os inúmeros problemas enfrentados para a consolidação do judiciário como instituição efetivamente democrática, o presente artigo busca demonstrar, através de um recorte teórico, como as duas principais correntes da magistratura brasileira, alternativa e conservadora, aproximam ou distanciam os indivíduos brasileiros da condição de cidadãos.
\end{abstract}

Palavras-chave: Cidadania; Direitos Civis; Direito à Justiça; Judiciário; Magistratura.

\begin{abstract}
The process of acquiring civil, political and social rights and the possibility of configuring a full citizen is a current debate in the academic field. Added to this, the desire to fortify political institutions so that a more egalitarian society can be perceived is subject both in the academy and in the plan of implementation of public policies and social development. Within the field of civil rights, the right to justice has proved to be an important factor in the inaccessibility of Brazilian individuals to the status of full citizens, based on the concept addressed by T. H. Marshall. Notwithstanding the numerous problems faced in consolidating the judiciary as an effectively democratic institution, this article aims to demonstrate, through a theoretical review, how the two main currents of the Brazilian judiciary, alternative and conservative, approach or distance Brazilian individuals from the condition of citizens.
\end{abstract}

Keywords: Citizenship; Civil Rights; Right to Justice Judiciary; Magistrature.

\section{1- Introdução}

Thomas H. Marshall (1967), ao analisar a Inglaterra dos séculos XVIII, XIX E $\mathrm{XX}$, propõe que o conceito de cidadania está ligado à ideia de sentimento de pertencimento a uma nação e à aquisição e gozo de direitos civis, políticos e sociais. Dentre esses direitos, são os civis, representados, sobretudo, pela liberdade de ir e vir,

\footnotetext{
${ }^{1}$ Mestrando em Ciências Sociais, Departamento de Ciências Sociais da Pontifícia Universidade Católica de Minas Gerais. Graduado em Direito, Faculdade Mineira de Direito da Pontifícia Universidade Católica de Minas Gerais. Contato: halbergaria@gmail.com
} 
liberdade de imprensa, pensamento e fé, direito à propriedade e de incluir contratos REVISTA ALAMEDAS V Vol. 5, n. 1, 2017 válidos e o direito à justiça, a base dos outros direitos.

O direito à justiça, pertencente ao grupo dos direitos civis, é o direito de defender e afirmar todos os direitos em termos de igualdade com os outros pelo devido encaminhamento processual. Este direito tem como base o princípio da igualdade, pois não há como alcançar justiça social sem que haja igualdade entre os indivíduos. (MARSHALL, 1967). O princípio da igualdade, também chamado de princípio da isonomia, significa igualdade de todos perante a lei. Está previsto no art. $5^{\circ}$, "caput", da Constituição Federal, segundo o qual todos são iguais perante a lei, sem distinção de qualquer natureza. De acordo com tal princípio, não deve haver distinção de classe, grau ou poder econômico entre os homens no momento de aplicação da lei.

Dentro desse contexto, busca-se demonstrar, através de um recorte teórico, o papel da magistratura brasileira, no curso da configuração de um cidadão pleno, a partir do conceito desenvolvido por Marshall. O foco da atuação da magistratura, no presente artigo, se dá no âmbito do sistema de justiça penal.

\section{2- Cidadania e Poder Judiciário- O mínimo jurídico de T. H. Marshall}

Desde a independência do Brasil foi observada a ampliação do acesso dos indivíduos aos direitos políticos, no período imperial, e aos direitos sociais, na Era Vargas. Todavia, esses progressos não escondem o longo caminho que o país ainda deve percorrer, sobretudo no que diz respeito aos direitos civis. Uma das razões para a dificuldade de consolidação, na prática, dos direitos civis, pode estar relacionada com o percurso da cidadania no Brasil (CARVALHO, 2013). Cidadania, a partir do conceito desenvolvido por T.H. Marshall, “compreende a lealdade de homens livres, imbuídos de direitos e protegidos por uma lei comum. Seu desenvolvimento é estimulado tanto pela luta para adquirir tais direitos, quanto pelo gozo dos mesmos, uma vez adquiridos" (MARSHALL, 1967, p.83). Esse conceito de cidadania foi desenvolvido por Marshall (1967), a partir da análise do período histórico inglês dos séculos XVIII, XIX e XX em que se pesquisou a sequência de aquisição de direitos civis, políticos e sociais. De acordo com o autor (1967),

o elemento civil é composto dos direitos necessários à liberdade individua 1liberdade de ir e vir, liberdade de imprensa, pensamento e fé, direito à propriedade e de incluir contratos válidos e o direito à justiça (...) por elemento político se deve entender o direito de participar no exercício do poder político, como membro de um organismo investido de autoridade política ou como um eleitor dos membros de tal organismo (...) o elemento social se refere a tudo o que vai desde o direito a um mínimo de bem-estar econômico e segurança ao direito de participar, por completo, na herança social e levar uma vida civilizada de acordo com os padrões que prevalecem na sociedade (MARSHALL, 1967, pg.84).

De acordo com Mendes (2005), este modelo construído por Marshall postula ter surgido, a partir da ideia de cidadania, uma igualdade jurídica básica que está associada à participação de cada um na sociedade. A cidadania seria a atribuição de um mínimo de direitos e deveres a todos os indivíduos que tivessem um vínculo com o Estado. Este 
mínimo, com o tempo, foi sendo ampliado com a atribuição de mais direitos a cada um REVISTA ALAMEDAS Vol. 5 n. 1,2017 e-ISSN 1981-025 3 em função de seu vínculo com o Estado. Assim, a ideia do mínimo jurídico comum a todos os que fazem parte do Estado é inerente à condição de cidadania. (MENDES, 2005)

Nesse viés, a igualdade jurídica é, no modelo de Marshall, um pressuposto de cidadania. Marshall enfatiza que esta igualdade básica não é incompatível com as diferenças existentes entre os vários níveis econômicos da sociedade (MARSHALL, 1967). Assim, a desigualdade das classes sociais, gerada pelo sistema capitalista, pode ser aceitável, desde que a igualdade jurídica, própria da cidadania, seja reconhecida.

Como informado, conceito de cidadania plena, segundo Marshall (1967), pode ser dividido em três aspectos: cidadania civil, política e social.

O elemento civil da cidadania é composto da possibilidade do exercício de todos os direitos necessários ao gozo da liberdade individual: "liberdade de ir e vir, de imprensa, de pensamento, de fé, o direito à propriedade, o direito de concluir contratos válidos, e, especialmente, o direito à justiça" (Marshall, p.63, 1967).

$\mathrm{O}$ direito à justiça, pertencente aos direitos civis, assegura a defesa e o exercício de todos os outros direitos em igualdade de condições, observado o encaminhamento processual. De acordo com Marshall (1967), as instituições mais intimamente ligadas ao aspecto civil da cidadania são os Tribunais de Justiça, já que sistema judiciário tem a competência de garantir aos cidadãos, de forma igualitária, o acesso aos direitos civis.

O elemento político da cidadania, materializada pela conquista dos direitos políticos, na Inglaterra, "difere dos direitos civis tanto no tempo, quanto no seu caráter" (MARSHALL, 1967, p. 69). Sua formação data do início do século XIX, quando os direitos civis já haviam se consolidado.

Na Inglaterra do século XIX, o mínimo jurídico comum atribuído a cada indivíduo vinculado ao Estado pelo instituto da cidadania só incluía os direitos civis, já que os direitos políticos constituíam privilégio de uma classe econômica limitada (MENDES, 2005). De todo modo, segundo Marshall (1967), a cidadania não era, nessa época, vazia de significado político, pois o acesso dos indivíduos aos direitos civis, e a consequente consciência de garantia das liberdades individuais o capacitavam a praticar atos políticos. O cidadão era livre para receber remuneração, adquirir propriedade, alugar uma casa, e, por consequência, lhe era permitido gozar quaisquer direitos políticos associados a esses feitos econômicos.

Como observado, no modelo inglês a inclusão dos direitos políticos ao mínimo comum da cidadania foi posterior à dos direitos civis, ocorrendo a sua ampliação no século XIX. No entanto, conforme demonstra Mendes (2005), apenas em 1918 os direitos políticos se consolidaram através da promulgação de uma lei que adotou o sufrágio universal e transferiu a base dos direitos políticos do substrato econômico, para a condição pessoal de cidadão. 
O elemento social da cidadania, por sua vez, toma forma no direito de participação

de todos na riqueza comum, informado pelo princípio jurídico da solidariedade social, materializando-se pelo direito de acesso à saúde, à educação e à previdência, entre outros (MENDES, 2005). De acordo com Mendes (2005), num primeiro momento, na Inglaterra, os direitos sociais constituíam um mínimo e não faziam parte do conceito de cidadania. Tanto nas iniciativas voluntárias quanto nas legais tinham o objetivo de diminuir o ônus da pobreza sem alterar o padrão de desigualdade (MENDES, 2005). Neste cenário, os direitos civis tornaram-se um instrumento pelo qual os indivíduos buscaram a elevação de sua condição econômica e social. Em outras palavras, foi possível a formulação de reivindicações de certos direitos sociais por estarem os indivíduos habilitados à capacidade de gozo dos direitos civis (MENDES, 2005).

Marshall (1967) noticia que, no final do século XIX, a Inglaterra assistiu ao primeiro grande avanço dos direitos sociais, sendo incorporados à condição de cidadania, passando a representar um aspecto que modificou o padrão da desigualdade social.

Marshall observa "que a cidadania tem alterado o padrão de desigualdade social" (MARSHALL, 1967, p.107).

Para o autor, a partir do conceito de cidadania, "a desigualdade pode ser tolerada numa sociedade desde que não crie descontentamento e só é aceitável se puder ser vista como estímulo para mudança e melhoria" (MARSHALL, 1967, p.107).

De acordo com o autor, há limitações inerentes ao sistema capitalista para que se alcance a igualdade material absoluta (MARSHALL, 1967). Segundo Marshall (1967), é possível conviver com uma desigualdade no sentido econômico, no entanto, no modelo de cidadania, é inconcebível conviver com a desigualdade jurídica.

O desenvolvimento da cidadania, no caso inglês, foi construído pela consolidação dos direitos civis, políticos e sociais. É possível, mantendo a fidelidade aos fatos históricos, atribuir o período de formação de cada um desses direitos a um século diferente: o aparecimento dos direitos civis data do século VIII; o dos direitos políticos data do século XIX; e o dos direitos sociais data do século XX.

Tendo como base o modelo proposto por Marshall, Carvalho (2013) demonstra que o percurso da cidadania no Brasil difere no tempo e na conquista dos direitos, quando comparado ao caso inglês.

\section{3- O percurso da cidadania no Brasil}

A cidadania brasileira teve origem e se atualiza por motivos e caminhos bastante diversos dos da cidadania de países europeus. Nesses países, a conquistas dos diferentes aspectos da cidadania, definidos por Marshall (1967), teve o objetivo primeiro de conter o arbítrio do poder real, resguardando, assim, os interesses individuais burgueses. Em nosso caso, os direitos dos cidadãos não foram fruto de conquista, mas de outorga da coroa, com a finalidade de promover a compensação da desigualdade jurídica 
naturalizada em nossa sociedade (CARVALHO, 2013). Entre nós, segundo Carvalho REVISTA ALAMEDAS a Vol. 5, n. 1, 2017 e-ISSN 1981-025 5 (2013), a construção da cidadania confunde-se com a luta pela democracia, que ganhou ímpeto após o fim da ditadura militar em 1985. No entanto, Carvalho (2013) demonstra que a conquista do direito ao voto não trouxe, automaticamente, garantia de liberdade, de participação, de segurança, de desenvolvimento, de emprego e de justiça social. Por outro lado, observou-se o aumento da violência urbana, o desemprego, o analfabetismo, a má qualidade na educação, a oferta inadequada dos serviços de saúde e saneamento e as desigualdades sociais e econômicas continuam sendo problemas centrais de nossa sociedade. Daí a conclusão, segundo Carvalho (2013), de que o exercício do voto não garantiu, por si só, a existência de governos atentos aos problemas básicos da população, isto é, a conquista de direitos políticos não levou à solução dos problemas sociais brasileiros.

Houve no Brasil, de acordo com Carvalho (2013), pelo menos duas diferenças importantes, se tomarmos como parâmetro o caso inglês. A primeira refere-se à maior ênfase nos direitos sociais, e a segunda refere-se à alteração da sequencia em que os direitos foram adquiridos.

Aqui, primeiro vieram os direitos políticos, no Império (1826-1881), posteriormente os direitos sociais, durante a Era Vargas (1930-1945), implantados em um período de supressão dos direitos políticos e civis.

Como o modelo sugerido por Marshall encerra uma lógica que vai além da cronologia, uma alteração desta lógica afeta a natureza da cidadania (CARVALHO, 2013). Desse modo, quando falamos de um cidadão inglês e de um cidadão brasileiro, não estamos falando exatamente da mesma coisa (CARVALHO, 2013). Carvalho (2013) entende que natureza histórica da cidadania tem a ver com a relação dos indivíduos com o Estado e com a nação. Surgem cidadãos na medida em que as pessoas passam a se sentir parte de um Estado, e com isto passam a ser sujeitos de determinados direitos e obrigações para com este Estado (CARVALHO, 20130). A maneira pela qual se formaram os Estados-nação condiciona a construção da cidadania. Em alguns países, como é o caso do Brasil, o Estado teve mais importância, pois o processo de difusão de direitos se deu principalmente a partir da ação estatal (CARVALHO, 2013). Todavia, a ação estatal para difusão de direitos civis, políticos e sociais, se deu através de avanços e recuos nos três âmbitos, devido a contextos sócio-políticos específicos. Por exemplo, direitos políticos: 1826-1881, o Brasil era mais "democrático" que os europeus nos parâmetros da época esse "excesso de democracia" foi cortado em 1881 quando se proibiu analfabetos de votar e se aumentou a renda anual para se ter direito a voto (somente em 1888 os analfabetos voltaram a ter esse direito); os direitos sociais só aparecem com Vargas, restritos aos trabalhadores urbanos formais; e os direitos civis aparecem na letra da lei sempre (aos amigos, tudo, aos inimigos a lei). Carvalho (2013) aponta que no Brasil, dos direitos que 
compõem a cidadania, são ainda os civis que apresentam as maiores deficiências em REVISTA ALAMEDAS
termos de seu conhecimento, extensão e e garantias. Segundo o autor (2013), a posição de classe define o acesso dos indivíduos aos direitos civis. De fato,

\begin{abstract}
do ponto de vista da garantia dos direitos civis, a sociedade brasileira pode ser divida em classes. Há os de primeira classe, os privilegiados, "os doutores", sendo invariavelmente representados pelos brancos, ricos, com formação universitária, que estão acima da lei e conseguem defender seus interesses através do dinheiro e do prestígio social. Ao lado dessa elite privilegiada, existe uma grande massa de "cidadãos simples", de segunda classe, que estão sujeitos aos rigores e aos benefícios da lei. São a classe média modesta, os trabalhadores assalariados com carteira de trabalho assinada, os pequenos funcionários, os pequenos proprietários urbanos e rurais. Podem ser brancos, pardos ou negros e normalmente têm até o segundo grau completo. Essas pessoas nem sempre têm a noção exata de seus direitos, e quando têm carecem dos meios necessários para os fazer valer. Finalmente, há os "elementos", utilizando do jargão policial, cidadãos de terceira classe. É a população das periferias das grandes cidades, trabalhadores urbanos e rurais sem carteira assinada, empregadas domésticas, camelôs, menores abandonados, mendigos. São quase invariavelmente pardos ou negros, analfabetos ou com educação fundamental incompleta. Esses não se sentem protegidos pela sociedade e pelas leis. (CARVALHO, 2013, p. 215).
\end{abstract}

O que Carvalho tenta demonstrar é a dificuldade que a grande maioria da população brasileira tem de se valer dos direitos civis. Na verdade, existe uma classe específica que tem acesso a esses direitos, os cidadãos de "primeira classe". Esse acesso só é possível, no entanto, por causa da posição de classe em que se encontram esses indivíduos. Os cidadãos de "segunda classe" e de "terceira classe", por outro lado, respondem pela dificuldade de acesso aos direitos de cidadania. Vale ressaltar, que entendemos por posição de classe a posição ocupada por um indivíduo na estrutura de classes. Esta definição se relaciona não apenas ao aspecto econômico, mas também à honra e ao prestígio social que os indivíduos possuem (WEBER, 2004).

Diante deste panorama, a cidadania brasileira enfrenta o desafio de fazer valer o princípio jurídico da isonomia, pelo qual todos devem ser iguais perante a lei e perante os tribunais, sem o que, torna-se inviável a atribuição de um mínimo jurídico comum a todos, especialmente no aspecto civil da cidadania. De acordo com Mendes (2005), no Brasil, o desafio consiste em fazer valer o instrumento jurídico como denominador comum, de forma isonômica, especialmente no que se refere à garantia e proteção dos direitos civis.

O fortalecimento do Poder Judiciário e sua afirmação como agente público responsável pela prestação jurisdicional e guardião do respeito às garantias individuais do cidadão, assim como a adequação dos serviços de segurança à prestação do serviço público que lhes compete, são conquistas emergenciais, sem as quais a cidadania brasileira se mostra ameaçada. Entretanto, como no mostra Carvalho (2013), a sociedade brasileira é dividida em classes, e é exatamente a posição do indivíduo na sociedade que irá determinar o seu acesso aos direitos de civis. Isto evidencia, que existe, de fato, uma dificuldade de acesso de grande parcela da população brasileira aos direitos civis, direitos esses que deveriam ser garantidos a todos, através da atuação do Poder Judiciário. 
Nesse contexto, percebe-se que a atuação dos magistrados é essencial para o

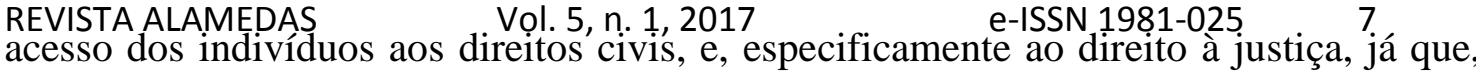
têm como atribuição principal a aplicação da lei. De acordo com a literatura, a magistratura brasileira está dividida entre duas correntes: a alternativa e a conservadora. A atuação dos magistrados, segundo a corrente que se identificam, podem aproximar ou distanciar os indivíduos ao direito à justiça e, portanto, à condição de cidadãos.

\section{4- As correntes alternativa e conservadora da magistratura brasileira}

No que diz respeito aos encarregados de aplicar e julgar os casos concretos, os juízes são atores centrais do sistema de justiça. Os magistrados têm sido objeto de estudos a respeito do conteúdo e motivação de suas decisões (AZEVEDO, 2014). De acordo com Azevedo (2014), as pesquisas sobre comportamento profissional, mentalidade dos juízes e origem social dos magistrados, colocaram em evidência a possibilidade de questionamento da neutralidade, abrindo um campo de indagações sobre as reais motivações das decisões judiciais.

As investigações empíricas sobre o perfil da magistratura e da atividade judicial têm servido para indicar que as decisões judiciais são influenciadas por uma série de variáveis, entre as quais são relevantes a ideologia política, a formação e a posição na hierarquia social e profissional dos magistrados (VIANNA ET AL., 1997). As conclusões apontam para a existência de uma dupla seletividade na atividade judiciária: seletividade na aplicação da lei, com maior probabilidade de punição para os setores sociais desfavorecidos econômica e culturalmente, e de favorecimento para as classes superiores, e seletividade na interpretação da lei, com a utilização pelo juiz de seu poder discricionário segundo suas opções políticas e ideológicas magistrados (VIANNA ET AL., 1997).

Para Carvalho (2010), em recente estudo sobre o papel dos atores do sistema penal, o produto da adesão política e jurídica ao punitivismo é a hipercriminalização da juventude pobre e analfabeta, conforme indicam os dados oficiais de encarceramento no país. Carvalho (2010) aponta que

O cotidiano forense experimentado no Brasil revela, via de regra, postura
judicial condescendente com o punitivismo, mormente nos momentos
processuais decisivos, fenômeno que se materializa na jurisprudência(...)
Dentre os inúmeros momentos-chave da atuação judicial, é possível visualizar
uma prática desvirtuada dos preceitos constitucionais, exemplificativamente;
na facilidade no deferimento e na manutenção de prisões cautelares; na
distribuição não paritária da prova, em detrimento dos direitos dos acusados;
na utilização de metarregras para acentuar a quantidade de pena nas sentenças
condenatórias; na resistência em aplicar alternaticas à prisão; e na dificuldade
em deferir os direitos dos apenados em sede de execução penal. (CARVALHO,
2010, p. 236) Carvalho (2010) demonstra ainda que os próprios agentes do sistema de justiça, especialmente magistrados e promotores de justiça, inviabilizam eventuais mudanças legislativas direcionadas à diminuição dos níveis de encarceramento. 
Todavia, conforme vimos anteriormente, o princípio da igualdade é fundamental REVISTA ALAMEDAS

desenvolvido por Marshall (1967). A lei deve valer e ser aplicada a todos e a qualquer um independente de qualquer fator. Quando não se pratica a igualdade, por óbvio que seja, estamos explicitando uma desigualdade, e, portanto, dificuldade de acesso de determinados indivíduos aos direitos civis de acordo com a posição de classe que ocupam.

Nesse aspecto, é crucial levar em conta a estratificação da sociedade brasileira. Souza (2009) entende que as classes sociais são definidas pela capacidade diferencial de incorporação de disposições e de conhecimento, ou seja, a incorporação de capital imaterial. Normalmente, apenas a herança material, pensada em termos econômicos de transferência de propriedade e dinheiro é percebida por todos. Imagina-se que a classe social, seus privilégios positivos e negativos, dependendo do caso, se transfere às novas gerações por meio de objetos materiais e palpáveis (SOUZA, 2009). Souza (2009) argumenta que,

o que não se percebe com clareza é a transferência de valores imateriais na
reprodução de classes sociais e de seus privilégios. São esses valores
imateriais, representados pelo estilo de vida, educação e formas de
comportamento, que irão determinar a condição de vida dos indivíduos e que
irão possibilitar a reprodução do próprio capital material e da desigualdade.
(SOUZA, 2009, p.18)

Souza (2009) aborda a respeito de valores imateriais que determinam formas de comportamento, e que influenciam o campo jurídico e criam certos padrões de diferenciação em processos judiciais. Aqui temos uma relação importante, pois, de acordo com Faria (2010), uma determinada classe fornece os agentes dominantes do campo jurídico, e essa classe é exatamente aquela que representa a elite do país, com as garantias de se obter desde a tenra idade, acesso à educação, cultura, e ao que Souza (2009) denomina capital imaterial. Vemos, desse modo, que a classe social está interligada ao campo jurídico. Mormente, procuradores do ministério público, magistrados e os próprios delegados de polícia, são, em sua maioria, compostos por indivíduos que tiveram acesso aos direitos de cidadania, os que Carvalho (2013), denominou de cidadãos de primeira classe. Por outro lado, nos parece viável dizer que os indivíduos sistematicamente submetidos ao sistema de justiça penal, nos dias de hoje, são aqueles representados pelo homem livre e pobre do século XIX, estudado por Maria Sylvia de Carvalho Franco (1964), e pelo negro, que teve o pior ponto de partida durante a transição do período escravocrata para a sociedade competitiva capitalista, como nos mostra Florestan Fernandes (1978).

Dito isto, lembremos que há duas correntes dominantes na magistratura brasileira. Uma primeira corrente, denominada alternativa, é caracterizada por aplicar a lei a partir de uma consideração mínima das condições e da realidade do indivíduo. A segunda corrente, denominada conservadora, está associada a uma cultura normativista, que segue 
estrita e rigorosamente os ritos e procedimentos formais. De acordo com Faria (2010), REVISTA ALAMEDAS para a corrente conservadora,

qualquer tentativa de interpretação capaz de identificar as diferenças e singularidades dos cidadãos, com o objetivo de promover a justiça social, de corrigir as disparidades econômicas e de neutralizar uma iníqua distribuição tanto de renda quanto de prestígio e de conhecimento, é esbarrada em uma mentalidade dogmática, formalista, temendo desviar-se da "certeza jurídica" ou da "segurança do processo" (FARIA, 2010, p.95)

Segundo Faria (2010), a corrente alternativa é, ainda, um movimento muito recente e a corrente conservadora da magistratura segue representando a maioria dos juízes no Brasil.

A corrente alternativa propõe uma subversão do ordenamento jurídico existente, através de uma prática, pelos magistrados, de utilização da lei e do direito em prol das classes sociais baixas. Ainda, para além das competências atribuídas à magistratura, os juízes da corrente alternativa participam como atores na sociedade, na luta por direitos, reivindicando um maior grau de acesso dos indivíduos excluídos e marginalizados, aos direitos civis.

Desse modo, juízes da corrente alternativa buscam adaptar as normas jurídicas existentes às necessidades dos setores populares, bem como atuar fora de suas competências, em favor dos indivíduos que figuram em classes sociais baixas.

Segundo Amilton Bueno de Carvalho (1993), a corrente alternativa da magistratura se baseia em um instrumental teórico e prático a ser utilizado por juízes que desejam atuar em prol da igualdade de fato dos cidadãos, de modo a ultrapassar os limites da igualdade formal, estabelecida na Constituição Federal de 1988. Segundo o autor, o direito é um indispensável instrumento para que as classes populares possam resistir à dominação e à exploração das classes dominantes. Nesse contexto, o Judiciário se torna o local disponível aos cidadãos para que lutem por seus direitos.

Na visão de Carvalho (1993), o uso alternativo do direito não se caracteriza pela negativa da lei, mas pela superação do legalismo jurídico, a saber, a estrita aplicação da lei, independente das circunstâncias do caso concreto. Esta forma de atuação é legitimada pelo conceito de igualdade trabalhado por Celso Antônio Bandeira de Mello (2003), em o Conteúdo Jurídico do Princípio da Igualdade.

Umas das principais críticas sofridas pelos magistrados da corrente alternativa é a de que estes juízes estariam pretendendo substituir os legisladores. Carvalho (1993) alega que, na realidade, os legisladores atuam de forma a beneficiar os indivíduos de classes sociais altas. Com isso, cabe ao Judiciário a obrigação de, no caso particular, alterar e corrigir situações não previstas ou mal previstas. Sendo uma das funções do Estado, o Judiciário deve agir em benefício da sociedade, sendo a lei apenas um referencial (CARVALHO, 1993).

Uma aplicação jurídica ao caso pode ser vislumbrada através da teoria da coculpabilidade do Estado, criada pelo jurista Eugenio Raul Zaffaroni. Tal teoria possibilita 
ao intérprete do direito penal que considere, no curso do processo, a parcela de REVISTA ALAMEDAS Vol. 5, n. 1, 2017 e-ISSN 1981-025 10

responsabilidade do Estado pela vulnerabilidade do indivíduo submetido à ação penal.

Conforme Zaffaroni (2001), dependendo do nível de responsabilidade do Estado sobre a vulnerabilidade do indivíduo, pode haver até a exclusão da culpabilidade do réu. Essa teoria representa um avanço na interpretação do direito penal, já que o Estado assume a sua responsabilidade tanto para com o indivíduo que praticou o delito, tanto para com a sociedade.

Juarez Cirino dos Santos (2002), ao analisar a co-culpabilidade do Estado formulada por Zaffaroni, entende que esta teoria "pode ser admitida como uma forma de valoração compensatória aos indivíduos inferiorizados por condições sociais adversas" (SANTOS, 2002, p.231). Nessa linha, o Estado deve arcar, pelo menos em parte, com as consequências de sua falha em oferecer ao cidadão as condições e os pressupostos mínimos de dignidade. Não seria correto que o Estado, competente para punir, através do Poder Judiciário, ou seja, competente para praticar o jus puniendi, não admitisse sua influência e parcela de responsabilidade ao limitar as garantias de acesso do indivíduo aos direitos de cidadania. Nesse sentido, Santos (2002) entende que "deve haver um compartilhar de responsabilidades entre o agente, o Estado e a sociedade" (SANTOS, 2002, p.233).

O artigo 66 do Decreto Lei 2848/40, o Código Penal brasileiro, prevê a possibilidade de aplicação da teoria da co-culpabilidade do Estado, formulada por Zaffaroni, conforme a seguir:

Art. 66 - A pena poderá ser ainda atenuada em razão de circunstância relevante, anterior ou posterior ao crime, embora não prevista expressamente em lei. (Redação dada pela Lei no 7.209 , de 11.7.1984)

De todo modo, importante frisar que a aplicação de uma atenuante ao crime, conforme a interpretação do artigo, se dá através do entendimento do magistrado ao caso concreto. A atenuante resultaria, na prática, na diminuição da dosimetria da pena em relação ao crime cometido.

Como exemplo, pode-se citar a decisão do Desembargador do Tribunal de Justiça de Minas Gerais, Alexandre Victor de Carvalho, ao julgar um crime de roubo, no ano de 2010:

APELAÇÃO - ROUBO - ARMA NÃO APREENDIDA - MAJORANTE INOCORRÊNCIA - CO-CULPABILIDADE - RECONHECIMENTO PARA FINS DE PROPORCIONALIDADE - NÃO-APLICABILIDADE - PENA REDUÇÃO - CIRCUNSTÂNCIAS JUDICIAIS - NOVA ANÁLISE. I - A majorante do uso de arma de fogo deve ser analisada sob o enfoque objetivo, ou seja, a razão de ser dela é exatamente a maior potencialidade lesiva do instrumento utilizado para a prática do roubo, devendo, portanto, ser verificada se a arma é hábil ou não para ofender a integridade física da vítima. II - É de se reconhecer a circunstância atenuante inominada, descrita no art. 66 do Código Penal, quando comprovado o perfil social do acusado, desempregado, miserável, sem oportunidades na vida, devendo o Estado, na esteira da co-culpabilidade citada por Zaffaroni, espelhar a sua responsabilidade pela desigualdade social, fonte inegável dos delitos patrimoniais, no juízo de censura penal imposto ao réu. III - As circunstâncias judiciais subjetivas contidas no art. 59 do CP devem ser 
analisadas em conformidade com os parâmetros doutrinário e jurisprudencial

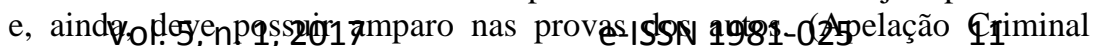
1.0443.05.025672-8/001, Rel. Des.(a) Alexandre Victor de Carvalho, $5^{\text {a }}$ CÂMARA CRIMINAL, julgamento em 14/09/2010, publicação da súmula em 29/09/2010) (grifo nosso)

Como observado, o magistrado analisa, ao julgar, o perfil social do réu, que, “desempregado, miserável, e sem oportunidades na vida", tem direito à aplicação de uma atenuante à pena que lhe será imposta. Este caso representa um exemplo prático da aplicação da teoria de Zaffaroni e da atuação da corrente alternativa da magistratura.

A corrente alternativa atua, desse modo, de forma a equilibrar as desigualdades sociais, aproximando os indivíduos brasileiros à condição de cidadãos. Nesse caso, observa-se o respeito ao mínimo jurídico comum em Marshall, e a possibilidade de acesso ao direito à justiça por indivíduos de classes sociais baixas.

A origem da interpretação da corrente conservadora, por sua vez, está relacionada às visões dualistas da sociedade brasileira, que tendem relacionar os problemas de desenvolvimento social e econômico a um passado subjugado ao colonialismo, pois “pensavam de forma disjuntiva os polos de 'tradição' e 'modernidade'- que colocavam num passado atrasado as peias para o pleno desenvolvimento" (CAZES, 2014, p.3). Para que possamos entender o modo de pensar da corrente conservadora, devemos recorrer à construção dualista do pensamento social brasileiro.

Dualismo, nas ciências sociais, está relacionado à noção de essencialismo culturalista que articula os conceitos de personalismo e patrimonialismo. A partir de um paradigma explicativo semelhante àquele do paradigma culture and personality, dominante na sociologia e antropologia americanas da primeira metade do século XX, (SOUZA, pg.2, 2003), o essencialismo culturalista parte de uma perspectiva em que a cultura é percebida como uma entidade homogênea, totalizante e auto-referida. Souza (2003) assevera que o essencialismo culturalista pode ser observado na obra Raízes do Brasil (HOLANDA, 1936). Esta, e as obras desenvolvidas por Gilberto Freyre (Casagrande e Senzala), Raymundo Faoro (Os donos do Poder) e Roberto da Matta (Carnavais, malandros e heróis) são referências no que diz respeito à construção do pensamento social brasileiro, seguindo a linha dualista para a interpretação das questões sociais.

Sergio Buarque de Holanda (2014) desenvolve, em Raízes do Brasil, as teses do "personalismo" e do "patrimonialismo" e o conceito de "homem cordial",

a lhaneza no trato, a hospitalidade, a generosidade, virtudes tão gabadas por estrangeiros que nos visitaram, representam, com efeito, um traço definido do caráter brasileiro, na medida, ao menos, em que permanece ativa e fecunda a influência ancestral dos padrões de convívio humano, informados no meio rural e patriarcal de traçando esses conceitos como as marcas fundamentais da cultura brasileira. Seria engano supor que essas virtudes possam significar "boas maneiras", civilidade. São, antes de tudo expressões legítimas de um fundo emotivo de um fundo emotivo extremamente rico e transbordante (HOLANDA, 2014, pg. 146,).

De acordo com Holanda (2014), o patrimonialismo é um desdobramento da família patriarcal na esfera pública, tornando a esfera pública influenciada por relações familiares; nas relações familiares predomina-se o personalismo, a vinculação de 
sentimentos no relacionamento com o outro; a cordialidade, por sua vez, é transversal, REVISTA ALAMEDAS Vol. 5, n. 1, 2017 $\quad$ e-ISSN 1981-025 12. está presente nas relações sociais e também é uma consequência do personalismo patriarcal. Em suma, pode-se dizer que a cordialidade significa uma total falta de compromisso com normas sociais objetivas, a subversão das regras em nome de interesses individuais mais imediatos. Holanda (2014) percebe que o "homem cordial" é o homem moldado pela família, em contraposição à esfera da política e da economia, que exigem disciplina, distanciamento afetivo e racionalidade instrumental. A cordialidade de Holanda se refere ao predomínio da emoção sobre a razão. Por conta disso, o Estado entre nós seria dominado pelo "patrimonialismo", ou seja, por uma gestão da política baseada no interesse particular por oposição ao interesse público. A cordialidade se opõe, portanto, à civilidade. Segundo o autor (2014),

Não era fácil aos detentores das posições públicas de responsabilidade,
formados por tal ambiente, compreenderem a distinção fundamental entre os
domínios do privado e do público. Assim, eles se caracterizam justamente pelo
que separa o funcionário "patrimonial" do puro burocrata conforme a definição
de Max Weber. Para funcionário "patrimonial", a própria gestão política
apresenta-se como assunto de seu interesse particular; as funções, os empregos
e os benefícios que dele aufere relacionam-se a direitos pessoais do funcionário
e não a interesses objetivos, como sucede no verdadeiro Estado burocrático,
em que prevalecem a especialização das funções e o esforço para se
assegurarem garantias jurídicas aos cidadãos. A escolha dos homens que irão
exercer funções públicas faz-se de acordo de acordo com a confiança pessoal
que merecem os candidatos, e muito menos de acordo com as suas capacidades
próprias. Falta a tudo a ordenação impessoal que caracteriza a vida no Estado
burocrático. (HOLANDA, 2014, p.146). Holanda (2014) percebe que o problema consiste em haver, no Brasil, um predomínio da cordialidade sobre a civilidade. Na civilidade, predomina-se o interesse público sobre o interesse particular. Para o autor, falta, no Brasil, uma impessoalidade necessária à atuação do Estado. Existe, desse modo, uma tensão entre esses dois pólos, cordialidade e civilidade.

Holanda (2014) entende a civilidade, nos moldes weberianos, como o processo de racionalização e impessoalização das relações humanas. Neste caso, a cordialidade lhe é contraposta como representação de relações humanas mais afetivas, vivas e menos abstratas.

Raymundo Faoro (2000), seguindo a linha dualista, defende a existência, na formação nacional brasileira, de um patrimonialismo estamental exercido por um estamento burocrático com origem em Portugal e que teria permanecido ao longo de toda a história brasileira. De acordo com Faoro (2000), desde o período colonial, o que caracterizou a formação nacional brasileira foi a existência de um poder central muito forte, que inibiu qualquer formação social espontânea e que determinou todas as mudanças sociais de "cima para baixo". Isto possibilitou um descolamento entre Estado e sociedade, ou, entre Estado e nação brasileiros. Com o descolamento, as relações entre Estado e nação não são mediadas pela representação de classes, em razão da existência de um estamento burocrático, que Faoro (2000) define como “[...] uma capa social 
rígida, com o exercício de privilégios jurídicos assegurados pela lei ou pela tradição REVIST, "NALAMEDAS Vol. 5, n. 1, 2017

$[\ldots]$ "(FAORO, 2000, p. 214).

Faoro (2000) ressalta a relação do estamento burocrático com o Estado patrimonial, na medida em que não há uma nítida separação entre o público e o privado por aqueles que exercem o poder estatal e por aqueles que detêm os privilégios. Assim, a formação brasileira seria marcada pelo patrimonialismo estamental, notoriamente uma confusão entre o público e o privado, e pela existência de privilégios para um determinado grupo de indivíduos.

De acordo com Souza (2003), a atualização mais importante da perspectiva dualista foi operada por Roberto DaMatta com a publicação de Carnavais, malandros e heróis. DaMatta pretende realizar uma nova interpretação do personalismo brasileiro ao associar a noção de "pessoa", basicamente o mesmo "homem cordial" de Holanda, definida como o agente com acesso a um certo capital de relações pessoais, à noção de "indivíduo", definido como o agente sem acesso ao referido capital social de relações sociais, adaptando a interpretação do personalismo a uma sociedade que vivia inegável processo de modernização (Souza, 2003).

DaMatta (1997) aborda o conceito do "jeitinho brasileiro", amplamente reproduzido pelo senso comum. O "jeitinho", como perversão da lei e da regra geral aplicável a todos, é como na noção de "homem cordial" de Holanda, um atributo do brasileiro de todas as classes sociais. O conceito de jeitinho é importante, pois diz respeito à possibilidade de o brasileiro agir fora dos limites da disciplina e da lei, já que vive em uma sociedade desigual. A ideia de DaMatta (1997) é a de que o Estado brasileiro não garante aos indivíduos o acesso aos seus direitos, e, por esse motivo, é necessário criar um novo direito que muitas vezes vai de encontro à ordem social.

Os magistrados da corrente conservadora entendem que essa forma de burlar a lei é um problema social tipicamente brasileiro. Uma das formas de se enfrentar o problema é utilizar a lei de forma a punir qualquer comportamento que está fora de seus limites.

De acordo com Souza (2003), a teoria desenvolvida por DaMatta cai no dualismo pois percebe a agora dinâmica e moderna sociedade brasileira, ainda que injusta e desigual, como dominada por relações sociais pré-modernas. Essas relações sociais prémodernas possuem toda a ambiguidade do sentimento e da emotividade levando a uma cultura do privilégio e da corrupção (SOUZA, 2003). Como assevera Souza (2003), a perspectiva dualista entende que é devido a essa soberania do passado sobre o presente que nos confrontamos com "solidariedades verticais baseadas no favor, subcidadania para a maior parte da população e abismo material e valorativo entre as classes que compõem nossa sociedade" (Souza, 2003, p.52).

Os conceitos de Holanda, Faoro e DaMatta, como dito, seguem uma interpretação dualista da formação social brasileira. De acordo com Coutinho (2009) essa interpretação 
exerce influência sobre a ala conservadora da magistratura. Por entenderem que os REVISTA ALAMEDASS Vol. 5, n. 1, $2017 \quad$ e-ISSN 1981-025 14 problemas da sociedade têm sua orígem em um passado marcado pelo domínio da emoção

sobre a razão, inclusive no âmbito institucional, além de uma naturalização da transgressão à lei típica de nossa sociedade, esses magistrados acreditam que a aplicação pura dos princípios jurídicos e da lei geram uma neutralidade (COUTINHO, 2009). Esta neutralidade, que se aproxima da ideia de imparcialidade na aplicação da lei, independentemente de quem está sendo julgado, cria uma suposição de que os juízes estão agindo de forma a remediar os problemas. Isto porque, ao aplicar a lei, o juiz não está agindo, supostamente, em beneficio de ninguém, mas exercendo sua função de forma impessoal.

De acordo com Coutinho (2009), a corrente conservadora tende a pensar que a solução dos problemas sociais e institucionais, inclusive os problemas enfrentados pelo Poder Judiciário, viria pela libertação de heranças do colonialismo que forjou nossa sociedade. Agindo desse modo, uma possível relação de antipatia e preconceito entre juízes e indivíduos submetidos a uma ação penal, torna-se invisível (Coutinho, 2009). Coutinho (2009) alerta que essa pretensão de neutralidade é uma das principais formas de legitimação da Justiça, pois a partir dela é criada a ideia de que todo o processo, no nosso caso, processo penal, é orientado não por conflitos e hierarquias próprias da realidade social, mas por princípios jurídicos que obedecem a critérios morais e possuem uma lógica e uma autonomia específicas ao campo jurídico. Ocorre que, conforme já citado, a posição de classe dos agentes do sistema de justiça penal difere da posição de classe dos indivíduos que são submetidos à aplicação da lei penal. Percebe a autora (2009) que o curso de um processo penal esconde que os conflitos e a desigualdade marcantes na nossa sociedade se prolongam nas instituições do Estado, o qual, na intenção de corrigi-los, muitas vezes os reproduzem cotidianamente (COUTINHO, 2009). Desse modo, uma visão opaca dos problemas sociais brasileiros, acaba por influenciar os juízes da corrente conservadora e, na prática, distancia os indivíduos submetidos a um processo penal do mínimo jurídico comum em Marshall. Nesse caso, reproduz-se uma desigualdade, ao distanciar, ainda mais, os indivíduos de classes sociais baixas à condição de cidadãos.

\section{4- Conclusão}

O presente artigo buscou demonstrar, através de um recorte teórico, como a corrente alternativa da magistratura brasileira tende a aproximar os indivíduos brasileiros da condição de cidadãos, e, como a corrente conservadora acaba por distanciar os indivíduos da cidadania. Vale lembrar que, de acordo com o estudo realizado por Faria (2010), a corrente conservadora compõe a face do Poder Judiciário brasileiro. Desse modo, é possível concluir que, se por um lado vislumbra-se um movimento em prol das classes sociais baixas, tornando o Poder Judiciário um local de afirmação e acesso ao direito à justiça e equilíbrio de desigualdades, por outro, o caminho a ser percorrido ainda 
é longo, já que uma interpretação dualista da sociedade brasileira influencia a maioria dos

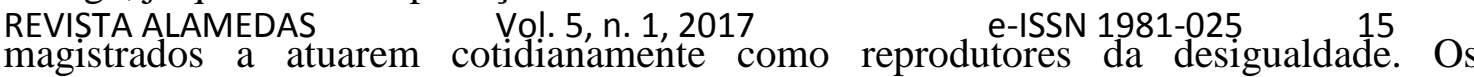
desdobramentos sociais e jurídicos de operações investigativas como a Lavo-Jato, podem indicar, para além de questões que envolvam afinidades partidárias, uma novidade na atuação do Poder Judiciário sobre os cidadãos de primeira-classe. Parece que, pela primeira vez, existe um movimento das instâncias judiciais que está atingindo, através da aplicação da lei, os indivíduos de classes sociais altas.

\section{Referências:}

Apelação Criminal 1.0443.05.025672-8/001, Rel. Des.(a) Alexandre Victor de Carvalho, $5^{\text {a }}$ CÂMARA CRIMINAL, julgamento em 14/09/2010, publicação da súmula em 29/09/2010.

AZEVEDO, Rodrigo G. de. Sociologia da administração da justiça penal. In. LIMA, Renato S. de; RATTON, José L.; AZEVEDO, Rodrigo G. de. Crime, polícia e justiça no Brasil. São Paulo, Contexto, 2014.

CARVALHO, Amilton B. de. Direito alternativo na jurisprudência. São Paulo: Acadêmica, 1993.

CARVALHO, José Murilo de. Cidadania no Brasil: o longo caminho, $17^{\mathrm{a}}$ edição, Rio de Janeiro: Civilização Brasileira, 2013. José Murilo de. Pontos e bordados. Belo Horizonte: Ufmg, 1998.

CARVALHO, S. de. O papel dos atores do sistema penal na era do punitivismo. Rio de Janeiro: Lumen Juris, 2010.

CAZES, Pedro. A sociologia histórica de Maria Sylvia de Carvalho Franco. Artigo. Crítica e Sociedade: revista de cultura política. v. 4, n. 2 Dossiê: pensamento social, desenvolvimento e desafios contemporâneos dez. 2014. ISSN: 2237-0579, acesso em 18 de fevereiro de 2016.

COUTINHO, Priscila. A ralé brasileira: quem é e como vive. Capítulo 14- A má-fé da Justiça- Belo Horizonte: Ufmg, 2009.

DaMATTA. Roberto. Carnavais, malandros e heróis: para uma sociologia do dilema brasileiro. 6 ${ }^{\text {a }}$ edição. Rio de Janeiro: Rocco, 1997.

FAORO, Raymundo. Os donos do poder. Volume 2, 10 a edição. São Paulo: Globo, 2000.

FARIA, José Eduardo. Direitos Humanos, Direitos Sociais e Justiça, $1^{\text {a }}$ Edição, São Paulo: Malheiros, 2010.

FERES, João Jr. Léxico da História dos conceitos políticos do Brasil. $2^{\mathrm{a}}$ edição. Belo Horizonte: Ufmg, 2014.

FERNANDES, Florestan, A integração do negro na sociedade de classes, vol. I, São Paulo: Ática, 1978.

FRANCO, M. S. de C. "Homens livres na velha civilização do café". Tese de Doutorado. Departamento de Ciências Sociais/Faculdade de Filosofia, Letras e Ciências Humanas, Universidade de São Paulo, 1964.

Homens Livres na Ordem Escravocrata. São Paulo: Instituto de Estudos Brasileiros, 1969.

HOLANDA, Sergio Buarque de. Raízes do Brasil, 26 edição, São Paulo: Companhia das Letras, 1995.

KANT DE LIMA, Roberto. Cultura jurídica e práticas policiais: a tradição inquisitorial. Revista Brasileira de Ciências Sociais, n. 10, v.4, jun. 1989, PP. 65-84.

MARSHALL. Thomas. H. Cidadania, classe social e status. Rio de Janeiro: Zahar Editores, 1967. 
MENDES, Regina L. T. Igualdade à brasileira: Cidadania como Instituto Jurídico no REVISTA ALAMEDAS Vol. 5, n. $1,2017 \quad$ e-ISSN 1981-025 16 Brasil. In. KANT DE LIMA, Roberto; MENDES, Regina L. T. Ensaios sobre a Igualdade Jurídica: Acesso à justiça criminal e direitos de cidadania no Brasil. Rio de Janeiro: Lumen Juris, 2005.

MELLO, Celso Antônio Bandeira de. O Conteúdo Jurídico do Princípio da Igualdade. 3. Ed. 11. Tiragem. São Paulo: Malheiros Editores, 2003.

SANTOS, Juarez C. dos. A moderna teoria do fato punível. 2. ed. Rio de Janeiro: Revan, 2002.

SANTOS, Wanderley G. Cidadania e justiça. Rio de Janeiro: Campus, 1977.

SOUKI, Lea. G. A atualidade do pensamento de T. H. Marshall no estudo da cidadania no Brasil. Artigo. Porto Alegre: Civitas, 2006. Disponível em http://revistaseletronicas.pucrs.br/ojs/index.php/civitas/article/view/21/6946. Acesso em 15 de janeiro de 2016.

SOUZA, Jessé. A ralé brasileira: quem é e como vive. Belo Horizonte: Ufmg, 2009. Jessé. (Não) Reconhecimento e subcidadania, ou o que é ser gente. São Paulo: Lua Nova, 2003.

VIANNA, L. et al. Corpo e alma da magistratura brasileira. Rio de Janeiro: Revan, 1997. WEBER, Max. Economia e Sociedade. Volume 2. São Paulo: UnB, 2004.

Zaffaroni, Eugenio Raul. Em busca das penas perdidas. Rio de Janeiro: Revan, 2001. 